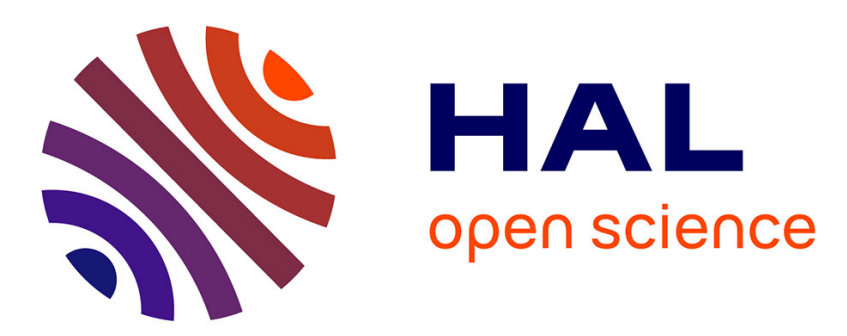

\title{
A comparison of prevalence and risk factor profiles of prolonged grief disorder among French and Togolese bereaved adults
}

Cyrille Kossigan Kokou-Kpolou, Jude Mary Cénat, Pari-Gole Noorishad, Sunyoung Park, Marie-Frédérique Bacqué

\section{To cite this version:}

Cyrille Kossigan Kokou-Kpolou, Jude Mary Cénat, Pari-Gole Noorishad, Sunyoung Park, MarieFrédérique Bacqué. A comparison of prevalence and risk factor profiles of prolonged grief disorder among French and Togolese bereaved adults. Social Psychiatry and Psychiatric Epidemiology, 2020, 55 (6), pp.757-764. 10.1007/s00127-020-01840-w . hal-03013417

\section{HAL Id: hal-03013417 https://hal.science/hal-03013417}

Submitted on 18 Nov 2020

HAL is a multi-disciplinary open access archive for the deposit and dissemination of scientific research documents, whether they are published or not. The documents may come from teaching and research institutions in France or abroad, or from public or private research centers.
L'archive ouverte pluridisciplinaire HAL, est destinée au dépôt et à la diffusion de documents scientifiques de niveau recherche, publiés ou non, émanant des établissements d'enseignement et de recherche français ou étrangers, des laboratoires publics ou privés. 


\title{
A comparison of prevalence and risk factor profiles of prolonged grief disorder among French and Togolese bereaved adults
}

\author{
Cyrille Kossigan Kokou-Kpolou' (1) Jude Mary Cénat ${ }^{2}$. Pari-Gole Noorishad². Sunyoung Park ${ }^{3}$. \\ Marie-Frédérique Bacqué ${ }^{4}$
}

Received: 14 November 2019 / Accepted: 3 February 2020

\begin{abstract}
Background With the introduction of the prolonged grief disorder (PGD) in the ICD-11 and most likely in the future DSM5-TR, there is clinical need to examine cultural variations in grief phenomenon. We tested whether grief symptoms differ cross-culturally by examining the prevalence rates and predictors of PGD among French and Togolese bereaved individuals. Methods The sample comprised 235 widowed persons ( 73 French and 162 Togolese participants). They all completed the Prolonged Grief Scale-11 items. There were no statistically significant differences between both groups in terms of sociodemographic information (except for education). However, they differed on loss-related characteristics. We used two different symptom-diagnostic tests to estimate the prevalence rates.

Results We found that French and Togolese bereavers reported almost similar PGD prevalence rates $(21.9 \%$ [95\% CI 0.13 , 0.36 ] and $15.4 \%$ [ $95 \%$ CI $0.10,0.23$ ], respectively for the first test, $26 \%$ [ $95 \% \mathrm{CI} 0.16,0.41]$ and $17.3 \%$ [95\% CI $0.12,0.25$, respectively for the second test). Through regression analyses, PGD severity was predicted by low education, being unemployed, long duration of a marital relationship, and traumatic death in the French sample, whereas it was predicted by being male and highly educated in the Togolese sample. Both groups only shared a recent bereavement period as a common risk factor.

Conclusions Even though French and Togolese widowed persons reported almost similar prevalence rates of PGD, etiology, risk, and protective factors are culturally distinctive. It is critical to consider cultural and individual differences when conducting research on diagnosis and intervention in cases of prolonged grief.
\end{abstract}

Keywords Prolonged grief disorder $\cdot$ Prevalence $\cdot$ Risk and protective factors $\cdot$ Cross-cultural research

\author{
Cyrille Kossigan Kokou-Kpolou \\ kkkcyrille@yahoo.fr \\ Jude Mary Cénat \\ jcenat@uottawa.ca \\ Pari-Gole Noorishad \\ pnoor033@uottawa.ca \\ Sunyoung Park \\ 1125sunny1987@gmail.com \\ Marie-Frédérique Bacqué \\ mfbacque@club-internet.fr \\ 1 Department of Psychology, University of Picardy Jules \\ Verne, 1 Chemin du Thil, CS52501, 80025 Amiens Cedex 1, \\ France \\ 2 School of Psychology, University of Ottawa, Ottawa, Canada \\ 3 Graduate School of Psychology, California Lutheran \\ University, Thousand Oaks, USA \\ 4 Department of Psychology, University of Strasbourg, \\ Strasbourg, France
}

\section{Introduction}

The loss of a loved person by death is an upsetting period in one's life. The majority of bereaved individuals come to terms with grief as time goes by. However, a minority of people, estimated at one person in ten, experience persistent and debilitating grief symptoms $[1,2]$ which expose them to heightened risks for mental and physical morbidity such as depression, anxiety, cardiovascular diseases, disabilities and, at worst, subsequent premature mortality [3-6]. These maladaptive grief conditions are called "prolonged grief disorder (PGD)" [7], a newly proposed psychiatric category in the eleventh edition of the International Classification of Diseases-ICD-11 [2, 8, 9]. PGD symptoms, among others, are persistent yearning for the deceased, intense pangs, feeling stunned or shocked by the loss, emotional numbness, 
avoidance of loss reminders that last over 6 months, and impacts on social, occupational, or daily functioning.

With the introduction of PGD in the ICD-11 and most likely in the future DSM-5-TR, ${ }^{1}$ implying its application cross-nationally in clinical practice, there is an important need for healthcare professionals working in intercultural settings to be well informed about how clients with diverse cultural backgrounds adapt to loss. In a recent meta-analysis, Lundorff et al. [1] estimated the pooled prevalence of PGD at $10.1 \%$ in studies conducted in Western countries (i.e., Australia, Denmark, Germany, the Netherlands, and the United States) and 9.2\% in those conducted in Eastern countries (i.e., China and Japan). This finding suggests little but significant variations in the severity of grief symptoms across cultures. Furthermore, there are abundant ethnographic data which have portrayed substantial cultural differences in grief reactions, grieving processes [10-16], and likely in risk factor profiles.

Until now, quantitative empirical data addressing this crucial issue are limited to differences between African American, Caucasian (e.g., US and Swiss), and Chinese bereaved persons [17-23]. Studies reporting the prevalence rates of PGD were those comparing African Americans and US Caucasians. With few exceptions [19, 20], most of these studies reported higher prevalence rates of PGD among the former group compared to the latter. Bonanno and colleagues [17, 22 ], in a prospective study, observed that Chinese bereaved individuals manifested more acute patterns of distress and grief processing in the early months of bereavement compared to their U.S. counterparts, but they also manifested more rapid recovery in adjustment than did the US participants. In contrast, Xiu et al. [23] found that Chinese individuals reported higher functional impairment compared to Swiss bereaved parents, but both samples showed similar PGD scores.

Furthermore, the above studies have scarcely documented the risk factors impacting PGD symptom severity. Lower levels of education and lower economic conditions have been reported among African Americans [20, 24], but such factors, although informative, are more attributable to racial socioeconomic inequalities experienced by diverse minority communities. In reviewing such findings in African Americans, some authors [14, 15, 25] asserted that the racial discrimination, also experienced through homicidal deaths, had a strong impact on their grieving experiences. As such, these studies might offer an incomplete picture of

\footnotetext{
${ }^{1}$ Prolonged grief disorder, alternatively called "persistent complex bereavement disorder", has been annexed to the Appendix of the fifth edition of the Diagnostic and Statistical Manual of Mental Disorders (DSM-5) for in-depth investigation to introduce it in the DSM-5-TR (text revision).
}

grief experiences in cross-cultural contexts. In this respect, Granek and Peleg-Sagy [25, p. 627] concluded that: "by selecting nondiverse research samples, we [researchers] are producing inadequate and limited knowledge about the grief experience."

Across a range of studies comparing Caucasian and Chinese participants, Xiu et al. [23] reported gender differences and lower economic conditions among Swiss, but not among Chinese bereaved groups as risk factors for PGD severity, suggesting that some risk factors are culturally distinctive. In the general literature, loss-related risk factors such as the cause of death (e.g., traumatic death) and short bereavement periods were also found to increase the likelihood of manifesting severe maladaptive grief symptoms [26-28], regardless of race or ethnicity [21, 29]. Some studies also found the quality of marital relationships (e.g., marital satisfaction) as an indicator of problematic grieving [19, 30]. Parkes [31 for review] found that the duration of marital relationships is a serious indicator of bereavement complication; elderly widowed people in UK with a longer marital relationship period might suffer from severe separation distress. Based on these findings, we examined the duration and satisfaction of marital relationships in the present study. These variables could be informative about gender-based functioning in marital relationships, which could be characterized by the importance of romantic love and emotional intimacy in individualistic societies compared to collectivistic societies [32].

As a whole, the cross-cultural empirical data we reviewed under-investigated the prevalence rates of PGD and have shed little light on factors that promote or impede adaptation to loss. Moreover, the dearth of studies is limited to differences between African American, Caucasian, and Chinese bereaved adults. Hence, the present study relied on a sample of French and Togolese (West African) conjugally bereaved adults and provided an opportunity to renew our view on the PGD issue. In the context of the inclusion of PGD in the ICD-11 and most likely in the future DSM-5-TR, the present study first sought to estimate the prevalence rates of PGD symptoms among French and Togolese bereaved adults. The second purpose was to identify risk factors associated with PGD symptom severity in both cultural groups with focus on sociodemographic and loss-related factors as well as factors associated with marital relationships.

\section{Methods}

\section{Procedure}

This research used comparative survey data collected in France and in Togo between 2015 and 2017. Both countries have the French language in common. The French participants were recruited through internet-based support groups 
( $n=52)$ and bereavement support groups in Catholic parish churches in Amiens, a northern city of Paris. In the latter group, we used a death registry (2014-2017) to contact potential participants who lost their spouse $(n=34)$. They were sent a postal package of printed questionnaires. Of the 34 participants, 21 returned the completed questionnaires within 3 weeks (response rate $=61.8 \%$ ). In Togo, the survey was conducted in three urban areas and seven rural locations. Participants were recruited through mutual-help groups of widowed people. During their monthly meeting, a package of printed questionnaires was distributed to them by the survey supervisors. They returned the completed questionnaires within 1 month (response rate $=87 \%$ ). To be eligible, Togolese participants had to have a sufficient education level to read and write. In both national groups, the inclusion criteria required having lost the partner at least 6 months before the date of the survey as criterion to determine the PGD diagnosis $[2,7]$. In compliance with the Declaration of Helsinki of 1975, as revised in 2008, all participants signed consent forms approved by the Institutional Ethics Committee of Universities of Amiens (France) and Lomé (Togo).

\section{Assessments}

Demographics. Participants from both countries provided demographic information including gender, age, education, and employment status.

Marital relationship. They also provided the duration of the marital relationship with the deceased and rated the extent to which they were satisfied with the relationship on a 5 -point scale $(1=$ unsatisfied to $5=$ very satisfied).

Loss-related characteristics. They included the age of the deceased, cause of death, and time passed since the loss.

Prolonged Grief Scale (PGS)-11. The French version of PGS was used to assess pathological grief symptoms (nr). The respondents rated 11 items on a 5-point Likert scale $(1=$ never to $5=$ always $)$, based on their reactions to their loss in the last month. Prior research on the cross-cultural psychometric properties of this measure confirmed its reliability [33]. In the present study, the Cronbach's $\alpha$ coefficient of PGS was 0.92 for the French sample, and 0.80 for the Togolese sample. Higher summed PGD scores (range 1-55) provide an index of the severity of potentially problematic grief.

\section{Statistical analysis}

Analyses were carried out using IBM SPSS 21.0 (SPSS Inc., Chicago, IL, USA). Descriptive statistics served to summarize demographics, loss-related characteristics, and PGD scores. Between-sample differences were determined using $t$ tests and Chi-square $\left(\chi^{2}\right)$ tests. To control for sample differences, as the two cross-national groups differ on some
Table 1 Items included in symptom-diagnostic tests

\begin{tabular}{|c|c|c|c|c|}
\hline \multirow{2}{*}{$\begin{array}{l}\text { PGS-11 items } \\
\text { Symptom (item) }\end{array}$} & \multicolumn{2}{|c|}{$\begin{array}{l}\text { PGD as per } \\
\text { Prigerson et al. }\end{array}$} & \multicolumn{2}{|c|}{ ICD-11-PGD } \\
\hline & Category & Item & Category & Item \\
\hline Yearning and longing & B & 1 & B & 1 \\
\hline Intense pangs & B & 2 & B & 2 \\
\hline Avoidance of reminders & $\mathrm{C}$ & 3 & - & - \\
\hline Emotional numbness & $\mathrm{C}$ & 7 & - & - \\
\hline Stunned/shocked & $\mathrm{C}$ & 9 & - & - \\
\hline Trouble accepting the death & $\mathrm{C}$ & 2 & $\mathrm{C}$ & 1 \\
\hline Difficulty moving on with life & $\mathrm{C}$ & 6 & $\mathrm{C}$ & 5 \\
\hline Life empty, meaningless & $\mathrm{C}$ & 8 & - & - \\
\hline $\begin{array}{l}\text { Feeling that a part of oneself has } \\
\text { died }\end{array}$ & $\mathrm{C}$ & 1 & $\mathrm{C}$ & 2 \\
\hline Bitterness or anger & $\mathrm{C}$ & 5 & $\mathrm{C}$ & 3 \\
\hline $\begin{array}{l}\text { Difficulty to trust others-not } \\
\text { assessed }\end{array}$ & $\mathrm{C}$ & 4 & - & - \\
\hline Survivor guilt — not assessed & $\mathrm{C}$ & - & $\mathrm{C}$ & 4 \\
\hline Functional impairment & $\mathrm{E}$ & 1 & $\mathrm{E}$ & 1 \\
\hline
\end{tabular}

The French version of PGS-11 does not include items on "difficulty to trust other" and "survivor guilt"

sociodemographic and loss-related variables, one-way analysis of covariance (ANCOVA) was used.

Prior to calculating the prevalence rates of "probable PGD caseness", we recorded scores on each PGS item as follows: a symptom was considered present if rated $4=$ "frequently" or $5=$ "always", and absent if rated 1, 2, or 3. Following this step, we used a two symptom-diagnostic tests: those earlier established by Prigerson et al. [7] (Model 1) and those recently proposed by Maciejewski et al. [2] from the ICD-11 PGD (Model 2). The first one requires endorsement of (a) one of the two Category B items, (b) at least five of nine Category $\mathrm{C}$ items, and (c) the Category $\mathrm{E}$ item. For the second one, at least three of five Category $\mathrm{C}$ items are considered. Table 1 presents the number and classification of items according to each model of symptom-diagnostic tests. In the French version of PGS-11, only eight items match the PGD symptoms as Prigerson et al.'s [7] model (except an item on "difficulty to trust others") and four match the ICD-11 PGD [9] (except an item on "survivor guilt"). Accordingly, in this study, for the Model 1, at least four of eight Category $\mathrm{C}$ items and for Model 2, at least two of four Category C items were considered. See O'Connor et al. [34] for a similar use of algorithms. The prevalence rates of PGD were estimated including 95\% confidence intervals (CI).

Finally, to identify risk factors for PGD symptom severity in each study group, we conducted two separate three-step hierarchical linear regression analyses. The first step included demographic information, the second step included marital relationship items, and the third step 
Table 2 Demographic and lossrelated characteristics of the two samples

\begin{tabular}{lccc}
\hline Variables & $\begin{array}{l}\text { French sample } \\
n(\%)\end{array}$ & $\begin{array}{l}\text { Togolese sample } \\
n(\%)\end{array}$ & Group difference $\left(t / \chi^{2}\right)$ \\
& & & \\
Gender & $61(83.6)$ & $143(88.3)$ & 0.98 \\
$\quad$ Female & $12(16.4)$ & $19(11.7)$ & -1.62 \\
$\quad$ Male & $53.64(7.27)$ & $56.04(11.69)$ & na \\
Age, M (SD) & & & \\
Education & $30(41.1)$ & $0(0.0)$ & 1.39 \\
$\quad$ University & $43(58.9)$ & $50(30.9)$ & -0.82 \\
Secondary school & $0(0.0)$ & $112(69.1)$ & $2.38^{*}$ \\
Primary school & $43(58.9)$ & $82(50.6)$ & 0.98 \\
Employment status & $30(41.1)$ & $80(49.4)$ & \\
Employed & $22.36(11.35)$ & $23.72(11.9)$ & $54.03^{* * *}$ \\
$\quad$ Unemployed & $4.48(0.65)$ & $4.18(0.94)$ & $-7.58^{* * *}$ \\
Duration of MR in year, M (SD) & $53.82(7.17)$ & $53.78(14.46)$ & \\
Satisfaction with MR, M (SD) & & & \\
Age of deceased, M (SD) & $48(65.75)$ & $28(17.28)$ & \\
Cause of death & $25(34.25)$ & $124(82.72)$ & \\
$\quad$ Brutal, violent death & $2.27(1.94)$ & $9.38(7.89)$ & \\
$\quad$ Natural expected, sudden death & &
\end{tabular}

The sample differences in the age, duration of MR, satisfaction with MR, and time since the loss were tested by $t$ tests. Categorical variables including gender, employment status, and the cause of the death were examined by $\chi^{2}$ tests. Education was not tested, given that two cell frequencies were equal to 0 , reflecting the large difference in level of education completed in both samples

$M R$ marital relationship, $M$ mean, $S D$ standard deviation

${ }^{*} p<0.05$

$* * p<0.01$

$* * * p<0.0001$

comprised loss-related risk factors. We then compared the three categories of variables that approached significance.

\section{Results}

Table 2 provides an overview of participant characteristics. The sample comprised 235 participants $(86.8 \%$ were women), including 73 French ( $83.6 \%$ female) and 162 Togolese ( $88.3 \%$ female) participants aged between 29 and 92 years $\left(M_{\text {age }}=55.30 ; \mathrm{SD}=10.56\right)$. There were no statistically significant differences between the samples in terms of gender, age, employment status, number of years in a marital relationship, and age of the deceased. However, they significantly differed on education, satisfaction with the marital relationship, cause of death, and time passed since the loss. Higher education attainment and relatively higher levels of satisfaction with the marital relationship were reported by French participants. A higher proportion of natural/expected deaths and a longer period passed since the death were reported by Togolese participants.

\section{Prevalence of prolonged grief disorder}

The overall mean score on PGS was $32.85(\mathrm{SD}=7.57$; range: $14-51)$. The mean score was $33.84(\mathrm{SD}=8.13$, range: 18-51) for French and 32.40 ( $\mathrm{SD}=7.29$, range: $14-49)$ for Togolese bereaved individuals. When using ANCOVA to control for between sample differences on demographics, indicators of marital relationship, and loss-related factors, the results showed no statistically significant differences between French and Togolese bereavers on the PGS score $\left(F_{1,227, \text { covariates }}=0.37, p=0.55\right)$.

As mentioned earlier, we followed two models of diagnostic criteria to estimate the prevalence rates of PGD. As a result of Model 1, 21.9\% (95\% CI 0.13, 0.36) of French and $15.4 \%(95 \%$ CI $0.10,0.23)$ of Togolese bereavers met criteria for a "probable PGD diagnosis". When following Model 2, 26\% (95\% CI 0.16, 0.41) of French and 17.3\% (95\% CI $0.12,0.25)$ of Togolese participants met criteria. Pairwise agreement between both symptom-diagnostic tests was almost perfect (kappa $=0.89$ ), according to the benchmark scale proposed by Landis and Koch [35]. In both cases, there were no statistically significant differences between 
Table 3 Results for separated hierarchical linear regression analyses to predict the PGD symptom severity in each sample

\begin{tabular}{|c|c|c|c|c|c|c|c|c|}
\hline \multirow[b]{2}{*}{ Variables } & \multicolumn{4}{|c|}{ French sample } & \multicolumn{4}{|c|}{ Togolese sample } \\
\hline & $R^{2}$ & $\Delta R^{2}$ & $F / \Delta F$ & Sig. variables & $\overline{R^{2}}$ & $\Delta R^{2}$ & $F / \Delta F$ & Sig. variables \\
\hline Step 1. Demographics (gender, age, education, and ES) & 0.19 & 0.19 & $4.02 * *$ & Education + ES & 0.07 & 0.07 & $3.14 *$ & Gender + Education \\
\hline $\begin{array}{l}\text { Step 2. Marital relationship (duration and satisfaction with } \\
\text { MR) }\end{array}$ & 0.28 & 0.09 & $8.28^{* *}$ & Duration of MR & 0.09 & 0.02 & $3.55^{+}$ & - \\
\hline $\begin{array}{l}\text { Step 3. Loss-related characteristics (age of the deceased, } \\
\text { cause of death, and time since loss) }\end{array}$ & 0.59 & 0.31 & $24.99 * * *$ & $\begin{array}{l}\text { Cause of } \\
\text { death + time } \\
\text { since loss }\end{array}$ & 0.12 & 0.03 & $2.48^{+}$ & Time since loss \\
\hline
\end{tabular}

$M R$ marital relationship, $E S$ employment status

${ }^{+} p<0.10$

$* p<0.05$

$* * p<0.01$

$* * * p<0.0001$

French and Togolese bereavers on the observed prevalence rates (all $p$ 's $>0.17)$.

\section{Risk and protection factors for PGD severity}

To identify predictors of PGD severity for each study group, two separate three-step hierarchical linear regression analyses were conducted. The results are shown in Table 3. For the French sample, the whole model was statistically significant and had larger variance $\left(R^{2}=0.59 ; F_{9,63}=11.97\right.$, $p<0.0001)$. Low education $(b=-5.25$ [CI 95\% -6.81 , -3.69 ], $p<0.0001)$, being unemployed $(b=-4.47$ [CI 95\% $-5.81,-3.12], p<0.0001)$, long duration of a marital relationship ( $b=0.11$ [CI 95\%: 0.04, 0.17], $p<0.01)$, traumatic death $(b=3.92$ [CI 95\% 2.28, 5.56], $p<0.0001)$, and short period passed since the death $(b=-0.05$ [CI 95\%-0.07, $-0.02], p<0.01$ ) increased PGD severity (Table 3 ).

For the Togolese sample, the whole model was also statistically significant, but with moderate variance explained $\left(R^{2}=0.12 ; F_{9,152}=3.07, p<0.01\right)$. Being male $(b=-1.65$ [CI 95\% - 3.09, - 0.21], $p=0.02)$, high education $(b=1.05$ [CI 95\% 0.06, 2.01], $p=0.04)$, and short bereavement period $(b=-0.01$ [CI 95\% $-0.02,0.01], p=0.03)$ predicted PGD severity. In summary, only a shorter period passed since the death was the common risk factor for elevated PGD symptoms in both groups.

\section{Discussion}

This study contributed to the limited literature examining problematic grieving and its contributing factors, crossculturally. To estimate the prevalence rates of PGD, we used the two symptom-diagnostic tests developed in the literature [2, 7]. In alignment with previous studies [2, 34], the results of pairwise agreement tests showed that both symptom-diagnostic tests displayed almost a similar predictive value in diagnosing PGD. As indicated by our results, French and Togolese bereavers reported similar prevalence rates of PGD and similar levels of overall grief symptom severity. The estimates of prevalence rates are close to those reported in the recent literature $[1,2,36]$ while considering that our samples restrictively focused on spousal bereavement. These findings also corroborate with some previous cross-cultural data $[19,20,23]$ which suggest that chronically debilitating distress following bereavement is a universal health concern.

However, we found complex configurations of risk factors associated with PGD symptom severity across the two cultural samples. A consistent common risk factor, regardless of the society, was that widowed persons recently afflicted by the loss were more at risk for chronically debilitating grief reactions. In other words, PGD symptom severity receded with time passing since the loss. This result aligns with certain previous studies [37, 38].

A second risk factor was education. However, French widowed persons with lower education levels and their Togolese counterparts with higher education attainment were more at risk for PGD symptom severity. Low education has been reported in many previous studies [37, 39, 40]. Our result is congruent with and reinforces these studies. In addition, low education and unemployment after spousal bereavement drastically increase the risk for PGD symptoms severity among French bereavers. This result is not typical for problematic grief, since the additive and interactive effects of both demographic variables on health and wellbeing in high-industrialized countries are well established [41]. From the perspective of a dual process model of coping with bereavement $[42,43]$, unemployment may diminish the opportunity to distract one's attention from post-bereavement distress and to recover rapidly. Thus, widowed persons with no professional occupation are more likely to deal with 
overwhelming intrusive rumination about the deceased. In the Togolese sample, by contrast, widowed persons with higher education were those meeting difficulties to adequately adjusting to the loss. If our findings are accurate, this is the second time this finding is reported in recent bereavement literature. A similar finding was reported by He et al. [44] among bereaved Chinese adults. These authors found that individuals with high school and postgraduate degrees exhibited higher prolonged grief symptoms than those with undergraduate degrees. Future studies could help to clarify these findings. Nevertheless, we argue that in collectivist societies, higher educated individuals may be more exposed to adverse life events because they tend to be disconnected from their community support.

Other specific risk factors included the number of years of the marital relationship and the cause of death among the French sample; gender among the Togolese sample. The duration of the marital relationship was less documented than marital satisfaction. This result confirmed the intuition of Parkes [31, for review] that guided the choice of this variable for the study. In a qualitative study, he earlier found that elderly widowed people in the UK having a longer marital relationship expressed severe separation distress symptoms involving memories of the affectional bonds with the deceased. Thus, we believe that this result among French bereavers is attributed to the importance of romantic love and emotional intimacy in individualistic societies compared to collectivistic ones [32]. Regarding the cause of death, our findings are also consistent with some previous evidence supporting that traumatic deaths trigger excruciating distress such as pervasive intrusive thoughts and images associated with circumstances of the death [26-28]. However, it should be noted that this factor was not found among Togolese bereavers. Most likely, specific mourning rituals addressing such deaths could have alleviated subsequent distress [45].

Finally, given the gender-related risk factor among the Togolese bereavers, we were surprised that men were at a more elevated risk for PGD than women. This is most likely the first time a study using a standardized measure of disturbed grief provided empirical support regarding higher bereavement complications among men compared to women. In the mid-1980s and 1990s, this hypothesis was debated at length. At that time, a review by Stroebe and Stroebe $[46,47]$ provided empirical evidence showing that widowed people presented severe depression symptoms secondary to the loss, but not acute and pathological grief. Our result needs to be interpreted within the West-African Togolese context, where social norms of masculinity discourage emotional expression in men and encourage their remarriage very soon after the loss. Our qualitative data which are not reported here, showed that most of the widowers in our sample decided to not remarry and suffered from being stigmatized by their communities. This situation generated more excruciating distress, which could be described as a "social pain,"; "a specific emotional reaction to the perception that one is being excluded from desired relationships or being devalued by wanted relationship partners or groups" [48, p. 202]. In sum, these findings strikingly portrayed social/contextual and individual differences in adjustment to bereavement.

\section{Strengths and limitations}

To the authors' knowledge, this is the first time a study using the standard gold measure of pathological grief examined, cross-culturally, the prevalence rates of PGD and its contributing factors among bereaved individuals from France and Togo. We specifically restricted our attention on intrapersonal and loss-related risk factors, providing a better understanding of cultural differences.

However, several limitations should be considered. First, the small size of the French sample limited a fully valid and comprehensive view of the French grief experience, compared to the Togolese one. Also, the mean age of French widowed persons did not reflect the mean age of life expectancy in the general population. This was partly due to the recruitment procedures. As a consequence, the generalizability of the results is limited. Moreover, the sampling differences between the two groups were important (e.g., education level, causes of death and length of bereavement). Although statistical methods such as ANCOVA were used to control these confounding effects, conventional inference statistics are only applicable for direct sample comparisons. Therefore, only the symptom pattern analysis is based on direct cross-country comparisons, and the final variance explanation analyses of the two groups were run independently. Other limitations were that the results are based on a cross-sectional design, self-reported data, and no clinical assessment interviews were conducted. In the future, a prospective longitudinal design paired with clinician ratings for grief symptoms would be of value.

\section{Conclusions}

Despite the mentioned limitations, we conclude that even though French and Togolese widowed persons exhibited almost similar prevalence rates of PGD, the etiology, risk, and protective factors are culturally distinctive. Current findings indicate important differences in intrapersonal and loss-related risk factors for PGD symptoms severity, such that clinicians working in intercultural contexts could provide proactive assistance for widowed persons from the cultures we studied. In other contexts, clinicians must be sensitive to cultural factors that may influence grief symptoms. Therefore, they should consider these factors not only 
in their evaluation, but also in their intervention. The cultural formulation interview is a useful tool for understanding the internal cultural aspects of grief and addressing them in therapy $[49,50]$. In sum, the study's findings underscored the extreme importance to consider cultural differences when conducting research on diagnosis and intervention in cases of prolonged grief.

Acknowledgements The authors are very grateful to all the participants from France and Togo who gave their time and energy to participate in the survey which made this study possible.

\section{Compliance with ethical standards}

Conflict of interest The authors declare that they have no conflicts of interest.

\section{References}

1. Lundorff M, Holmgren H, Zachariae R, Farver-Vestergaard I, O'Connor M (2017) Prevalence of prolonged grief disorder in adult bereavement: a systematic review and meta-analysis. J Aff Disord 212:138-149

2. Maciejewski PK, Maercker A, Boelen PA, Prigerson HG (2016) "Prolonged grief disorder" and "persistent complex bereavement disorder", but not "complicated grief", are one and the same diagnostic entity: an analysis of data from the Yale Bereavement Study. World Psych 15:266-275. https://doi.org/10.1002/ wps. 20348

3. Clayton JP (1979) The squelae and non squelae of conjugal bereavement. Am J Gen Psych 136:530-534

4. Knowles LM, Ruiz JM, O'Connor MF (2019) A systematic review of the association between bereavement and biomarkers of immune function. Psychosom Med 81:415-433. https://doi. org/10.1097/PSY.0000000000000693

5. Prigerson HG, Bierhals AJ, Kasl SV et al (1997) Traumatic grief as risk factor for mental and physical morbidity. Am J Psych 154:616-623

6. Prior A, Fenger-Grøn M, Davydow DS, Olsen J, Li J, Guldin MB, Vestergaard M (2017) Bereavement, multimorbidity and mortality: a population-based study using bereavement as an indicator of mental stress. Psychol Med 48:1437-1443

7. Prigerson HG, Horowitz MJ, Jacobs SC et al (2009) Prolonged Grief Disorder: Psychometric validation of criteria proposed for DSM-V and ICD-11. PLoS Med 6:e1000121. https://doi. org/10.1371/journal.pmed.1000121

8. Maercker A, Brewin CR, Bryant RA et al (2013) Proposals for mental disorders specifically associated with stress in the international classification of diseases-11. Lancet 381:1683-1685

9. World Health Organization (2016) ICD-11 beta draft website [Information]. https://icd.who.int/browse11/1-m/en\#/http://id.who. int/icd/entity/1183832314

10. Cowles KV (1996) Cultural perspectives on grief: an expanded concept analysis. J Adv Nurs 23:287-294

11. Eisenbruch M (1984) Cross-cultural aspects of bereavement I: a conceptual framework for comparative analysis. Cult Med Psych 8:283-309. https://doi.org/10.1007/BF55172

12. Eisenbruch M (1984) Cross-cultural aspects of bereavement II: Ethnic and cultural variations in the development of bereavement practices. Cult Med Psych 8:315-347. https://doi.org/10.1007/ BF00114661
13. Rosenblatt PC (2013) The concept of complicated grief: lessons from other cultures. In: Stroebe M, Schut H, Bout J (eds) Complicated grief: Scientific foundations for health professionals. Routledge, New York, pp 27-39

14. Rosenblatt PC (2017) Researching grief: cultural, relational, and individual possibilities. J Loss Trauma 22:617-630. https://doi. org/10.1080/15325024.2017.1388347

15. Rosenblatt PC, Wallace BR (2005) African American grief. Routledge, New York

16. Rosenblatt PC, Walsh RP, Jackson DA (1976) Grief and mourning in cross-cultural perspective. Human Relations Area Files Press, New Haven

17. Bonanno GA, Papa A, Lalande K, Zhang N, Noll JG (2005) Grief processing and deliberate grief avoidance: a prospective comparison of bereaved spouses and parents in the United States and the Peoples Republic of China. J Couns Clin Psych 73:86-98

18. Burton CL, Yan OH, Pat-Horenczyk R, Chan ISF, Ho S, Bonanno GA (2012) Coping flexibility and complicated grief: a comparison of American and Chinese samples. Depres Anx 29:16-22. https:// doi.org/10.1002/da.20888

19. Carr DS (2004) African American/Caucasian differences in psychological adjustment to spousal loss among older adults. Res Aging 26:591-622

20. Cruz M, Scott J, Houck P, Reynolds CF, Frank E, Shear MK (2007) Clinical presentation and treatment outcome of African Americans with complicated grief. Psych Serv 58:700-702

21. Goldsmith B, Morrison RS, Vanderwerker LC, Prigerson HG (2008) Elevated rates of prolonged grief disorder in African Americans. Death Stud 32:352-365. https://doi.org/10.1080/07481 180801929012

22. Pressman DL, Bonanno GA (2007) With whom do we grieve? Social and cultural determinants of grief processing in the United States and China. J Soc Pers Relat 24:729-746. https://doi. org $/ 10.1177 / 0265407507081458$

23. Xiu D, Maercker A, Woynar S, Geirhofer B, Yang Y, Jia X (2016) Features of prolonged grief symptoms in Chinese and Swiss bereaved parents. J Nerv Mental Dis 204:693-701. https://doi. org/10.1097/NMD.0000000000000539

24. Van P, Meleis AI (2003) Coping with grief after involuntary pregnancy loss: perspectives of African American women. J Obst Gyn Neo Nurs 32:28-39

25. Granek L, Peleg-Sagy T (2017) The use of pathological grief outcomes in bereavement studies on African Americans. Transc Psych 54:384-399. https://doi.org/10.1177/1363461517708121

26. Hibberd R, Elwood LS, Galovski TE (2010) Risk and protective factors for posttraumatic stress disorder, prolonged grief, and depression in survivors of the violent death of a loved one. J Loss Trauma 15:426-447. https://doi.org/10.1080/15325 024.2010 .507660

27. Kristensen P, Weisæth L, Heir T (2012) Bereavement and mental health after sudden and violent losses: a review. Psychiatry 75:76-97. https://doi.org/10.1521/psyc.2012.75.1.76

28. van Denderen M, de Keijser J, Kleen M, Boelen PA (2015) Psychopathology among homicidally bereaved individuals: a systematic review. Trauma Viol Abuse 16:70-80. https://doi. org/10.1177/1524838013515757

29. Feigelman W, Jordan JR, Gorman BS (2009) How they died, time since loss, and bereavement outcomes. OMEGA J Death Dying 58:251-273

30. Bonanno GA, Wortman CB, Lehman DR, Tweed RG, Haring M, Sonnega J, Carr D, Nesse R (2002) Resilience to loss and chronic grief: a prospective study from pre-loss to 18 months post-lost. J Pers Soc Psych 83:1150-1164

31. Parkes CM (1997) Bereavement and mental health in the elderly. Rev Clin Geront 7:47-53. https://doi.org/10.1017/S095925989 7000051 
32. Dion K, Dion K (1993) Individualistic and collectivistic perspectives on gender and the cultural context of love and intimacy. $\mathrm{J}$ Soc Issues 43:53-69

33. Kokou-Kpolou K, Tremblay J, Moukouta CS, Baugnet L (2017) Unexpected death, religious coping and conjugal bereavement outcomes in Africa (Togo). Ment Health Relig Cult 20:766-782

34. O'Connor M, Lasgaard M, Larsen L, Johannsen M, Lundorff M, Farver-Vestergaard I, Boelen PA (2019) Comparison of proposed diagnostic criteria for pathological grief using a sample of elderly bereaved spouses in Denmark: perspectives on future bereavement research. J Aff Dis 251:52-59

35. Landis JR, Koch GG (1977) The measurement of observer agreement for categorical data. Biometrics 33:159-174. https://www. jstor.org/stable/2529310

36. Pohlkamp L, Kreicbergs U, Prigerson HG, Sveen J (2018) Psychometric properties of the prolonged grief disorder-13 (PG-13) in bereaved Swedish parents. Psych Res 267:560-565

37. Milic J, Muka T, Ikram MA, Franco OH, Tiemeier H (2017) Determinants and predictors of grief severity and persistence: the rotterdam study. J Aging Health 29:1288-1307. https://doi. org $/ 10.1177 / 0898264317720715$

38. Newson RS, Boelen PA, Hek K, Hofman A, Tiemeier H (2011) The prevalence and characteristics of complicated grief in older adults. J Aff Dis 132:231-238. https://doi.org/10.1016/j. jad.2011.02.021

39. Boelen PA, Reijntjes A, Djelantik AAAMJ, Smid GE (2016) Prolonged grief and depression after unnatural loss: latent class analyses and cognitive correlates. Psych Res 240:358-363

40. Nielsen MK, Neergaard MA, Jensen AB, Vedsted P, Bro F, Guldin MB (2017) Predictors of complicated grief and depression in bereaved caregivers: a nationwide prospective cohort study. J Pain Symp Manag 53:540-550. https://doi.org/10.1016/j. jad.2019.01.056
41. Cooper D, McCausland WD, Theodossiou I (2006) The health hazards of unemployment and poor education: the socioeconomic determinants of health duration in the European Union. Econom Hum Biol 4:273-297

42. Stroebe M, Schut H (1999) The dual process model of coping with bereavement: rationale and description. Death Stud 23:197-224

43. Stroebe M, Schut H (2010) The dual process model of coping with bereavement: a decade on. OMEGA J Death Dying 61:273-289

44. He L, Tang S, Yu W, Xu W, Xie Q, Wang J (2014) The prevalence, comorbidity and risks of prolonged grief disorder among bereaved Chinese adults. Psych Res 219:347-352

45. Kokou-Kpolou K, Mbassa Menick D, Moukouta CS, Baugnet L (2017) Implications du corps et du lien social dans les thérapies traditionnelles du deuil pathologique au Togo [Implications of the body and social bond in traditional therapies for pathological grief in Togo]. L'autre, cliniques, cultures et sociétés 18:47-56

46. Stroebe MS, Stroebe W (1983) Who suffers more? Sex differences in health risks of the widowed. Psychol Bull 93:297-301

47. Stroebe M, Stroebe W, Schut H (2001) Gender differences in adjustment to bereavement: an empirical and theoretical review. Rev Gen Psych 5:62-83

48. MacDonald G, Leary MR (2005) Why does social exclusion hurt? The relationship between social and physical pain. Psychol Bull 131:202-223

49. American Psychiatric Association (2013) Diagnostic and statistical manual of mental disorders, 5th edn. American Psychiatric Publishing, Arlington

50. Smid GE, Groen S, de la Rie S, Kooper S, Boelen PA (2018) Toward cultural assessment of grief and grief-related psychopathology. Psych Serv 69:1050-1052 